\title{
Addendum: Heme is involved in microRNA processing
}

Michael Faller, Michio Matsunaga, Sheng Yin, Joseph A Loo \& Feng Guo

Nat. Struct. Mol. Biol. 14, 23-29 (2007); published online 10 December 2006; addendum published after print 6 October 2008

Here we report that the calibration peaks of size-exclusion chromatography (SEC) were misassigned in our paper. The estimated molecular weights based on the new calibration curve are larger than those reported (Table 1). However, our conclusions about oligomerization states of the heme-bound and heme-free NC1 and the NC9 proteins are supported by additional experimental evidence, and are unchanged. The heme-bound NC1 is a dimer, as was directly confirmed using ESI MS. NC9, and the heme-free NC1, is largely monomeric, as indicated by our unpublished ESI mass spectra. In addition, NC9 is similar to the monomeric DGCR8 core, as demonstrated by its crystal structure (Nat. Struct. Mol. Biol. 14, 847-853, 2007). In our paper, we proposed a cooperative trimer model in which the heme-free $\mathrm{NC1}$ dimer, as well as NC9, further trimerizes upon association with the pri-miR-30a RNA. This model is supported by the new SEC estimates. Therefore, SEC seems to systematically overestimate the molecular weights of DGCR8 proteins and protein-RNA complexes, probably due to their elongated shapes. The new estimated molecular weight of the heme-free NC1 in complex with pri-miR-30a is consistent with a model in which three heme-free NC1 molecules associate with one pri-miRNA, but this estimate is not conclusive. Further corroboration on the oligomerization state of the heme-free NC1 upon binding to pri-miRNAs is needed.

Table 1 Summary of SEC results with new estimates of molecular weights

\begin{tabular}{llllll}
\hline $\begin{array}{l}\text { Protein or protein-RNA } \\
\text { complexes }\end{array}$ & Figures in paper & $\begin{array}{l}\text { Elution volume } \\
(\mathrm{ml})\end{array}$ & $\begin{array}{l}\text { Previous estimates } \\
(\mathrm{kDa})\end{array}$ & $\begin{array}{l}\text { New estimates } \\
(\mathrm{kDa})^{\mathrm{a}}\end{array}$ & $\begin{array}{l}\text { Predicted molecular } \\
\text { weight }(\mathrm{kDa})\end{array}$ \\
\hline Heme-bound NC1 & 2a, 2b & 10.9 & 122 & 181 & 108 \\
Heme-free NC1 & 2a & 12.1 & 78 & 120 & 54 \\
NC1 C352A & 3b & 11.9 & 84 & 129 & 54 \\
Pri-miR-30a & 4c & 11.6 & 70 & 121 & 48 \\
Heme-bound & 4c & 8.5 & 310 & 379 & 372 \\
NC1-pri-miR-30a & & & & & \\
Heme-free & 4c & 9.8 & 170 & 234 & $156^{\mathrm{b}}$ \\
NC1-pri-miR-30a & & & & or 210c \\
NC9 & 6a & 15.3 & 23 & 40 & 29 \\
NC9-pri-miR-30a & 6d & 10.7 & 111 & 168 & 135 \\
\hline
\end{tabular}

aThe new calibration curves are $y=-0.1485 x+6.877$ for high-salt buffer with a $500-\mu$ injection loop, and $y=-0.1603 x+6.941$ for low-salt buffer with a $100-\mu$ injection loop, where $x=$ elution volume and $y=\log$ (molecular weight). bBased on a cooperative dimer model, in which two heme-free NC1 molecules bind to one pri-miR-30a RNA. 'Based on a cooperative trimer model, in which three heme-free NC1 associate with a pri-miR-30a. 